\title{
DINÂMICA DO USO E OCUPAÇÃO DO SOLO NO LITORAL DE MACAU-RN NO PERÍODO DE 1978 À 2008
}

\author{
Valdemberg Antônio Araújo dos Santos e Zuleide Maria Carvalho Lima ${ }^{1}$ \\ Universidade Federal do Rio Grande do Norte \\ E-mail: zuleide@ufrnet.com.br ${ }^{1}$
}

Artigo submetido em abril/2011 e aceito em dezembro/2013

\section{RESUMO}

Este estudo foi desenvolvido no litoral setentrional do município de Macau, no estado do Rio Grande do Norte. Caracterizada por contribuições de águas oceânicas, alagando áreas de manguezais, aliado às condições climáticas e topográficas proporcionam um ambiente ideal para o desenvolvimento da atividade salineira. Inserida no contexto geológico da Bacia Potiguar, a região apresenta condições favoráveis para a produção de hidrocarbonetos e ainda condições naturais para a carcinicultura e pesca artesanal. Este trabalho analisa as transformações ocorridas no uso do solo, utilizando fotografias aéreas de 1978, Imagens Landsat 5 ETM de 1988,1998 e 2008 . Foi realizada uma analise temporal da dinâmica do uso do território e as transformações ocorridas na paisagem devido ao incremento das atividades produtivas. No campo observou-se que grandes áreas utilizadas anteriormente para a atividade salineira, hoje se encontram preparadas para a carcinicultura e que as áreas de exploração petrolífera ocupam salinas, praias e tabuleiros.

PALAVRAS-CHAVE: Uso do solo, Atividade salineira, Dinâmica temporal, Unidades geoambientais.

\section{DYNAMIC SOIL USE AND OCCUPATION IN MACAU-RN COASTLINE IN THE PERIOD 1978 TO 2008}

\begin{abstract}
This study was developed in the northern coast of the city of Macau, located in the State of Rio Grande do Norte. Characterized by contributions of oceanic water, flooding areas of swamps. Altogether, the climatic and topographical conditions provide an ideal environment for the development of saline activity. Inserted in the geologic context of the Potiguar Basin, the region presents favorable conditions for the production of hydro-carbons and natural conditions for shrimp breeding and artisanal fishing. This work analyzes the
\end{abstract}

transformations occurred in the land use, using air photographs of 1978, Landsat 5 ETM Images of 1988, 1998 and 2008. A temporal analysis of the dynamics of the use of the territory and the changes in the landscape due to the development of productive activities. In the field it was observed that great areas used previously for the saline activity, today it is prepared for shrimp breeding and that the areas of petroleum exploration occupy salt mines, beaches and trays.

KEYWORDS: land use, productive activities, salt activity, temporal dynamic, geoenvironmental unities. 


\section{DINÂMICA DO USO E OCUPAÇÃO DO SOLO NO LITORAL DE MACAU-RN NO PERÍODO DE 1978 À 2008}

\section{INTRODUÇÃO}

A área em estudo está situada na região Norte do Estado do Rio Grande do Norte, no município de Macau, entre os paralelos $5^{\circ} 03^{\prime} 18^{\prime \prime e ~} 5^{\circ} 08^{\prime} 47^{\prime}$ " de latitude Sul e $36^{\circ} 36^{\prime} 50$ "e $36^{\circ}$ $28^{\prime}$ 58" de longitude Oeste, distante aproximadamente $180 \mathrm{~km}$ da capital, Natal. (Figura 1). A principal via de acesso é a BR-406 (Natal-Macau), outras vias e a estrada asfaltada RN221(Macau-Guamaré). (Figura 1).

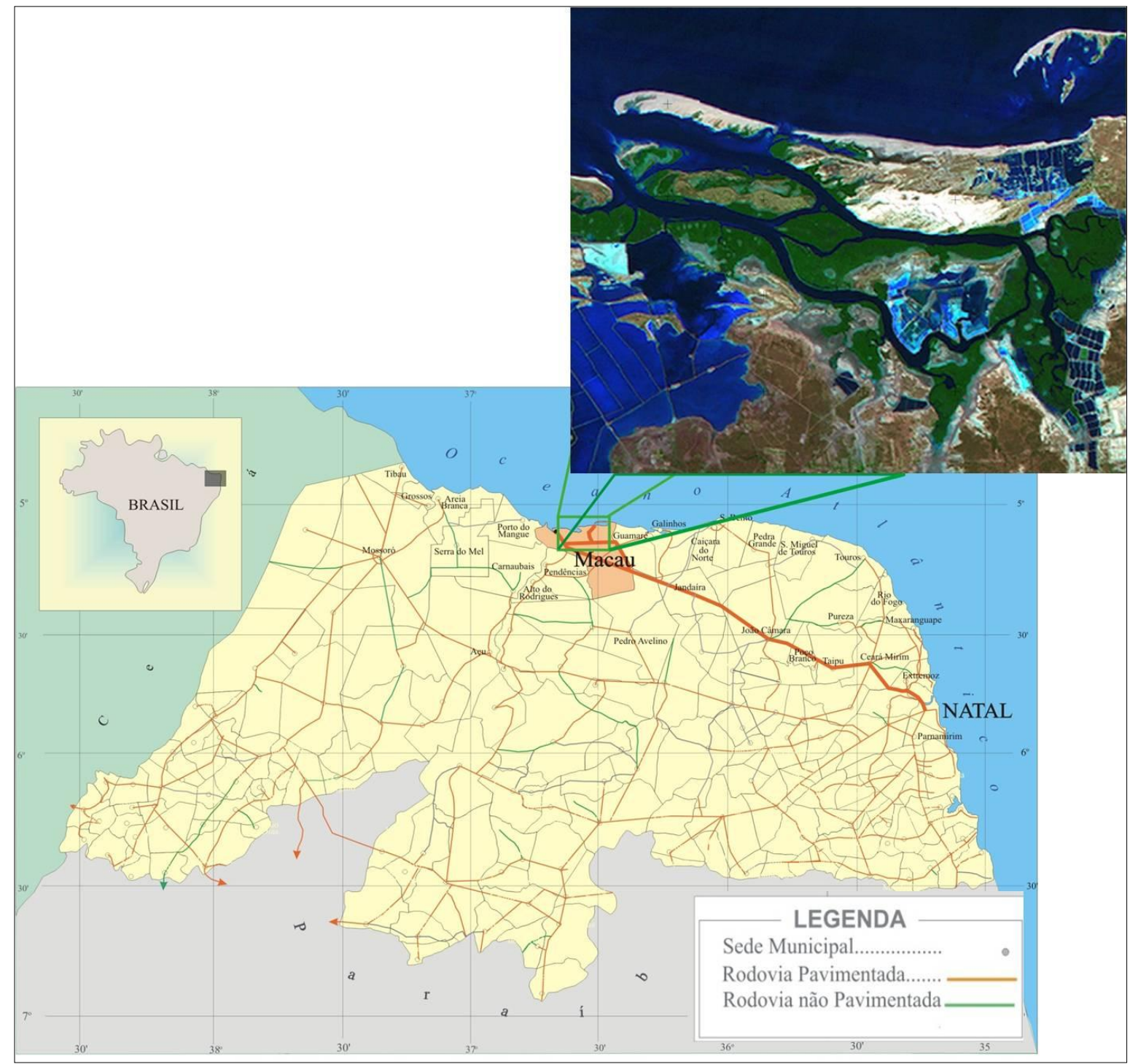

Figura 1: Localização da área de estudo. Fonte: IDEMA e Imagem Landsat 52007.

O presente trabalho visa analisar e comparar espacialmente a dinâmica do uso do solo no litoral setentrional de Macau-RN no período de 1978 a 2008, destacando o território das atividades extrativistas (sal, camarão, petróleo e gás), bem como identificando seus impactos socioambientais e ainda descrevendo as unidades geoambientais a luz da dinâmica temporal do processo de uso e ocupação do solo. 
O litoral do município de Macau é uma área sensível, especialmente no tocante aos aspectos naturais, pois está situada na interface entre o oceano e o continente, localizando-se num divisor de duas bacias hidrográficas (Bacia Piranhas-Assu e Bacia Hidrográfica Faixa Litorânea Norte) (SEMARH, 2008).

Assim, sendo notadamente uma área de interesse econômico para lazer e atividades econômicas produtivas, no caso especial das produções de sal, camarão, petróleo e gás, a fragilidade ambiental da área justifica estudos que contribuam para o uso racional e sustentável dos recursos naturais, que são de grande importância para a economia local, e que incitem a ponderação entre o conservar e produzir.

As mudanças e variações de fatores naturais morfodinâmicos afetaram constantemente a faixa costeira: Intensidade de ventos, correntes, altura de ondas, variação do nível da maré, formam as feições morfológicas locais, que vem modificando a paisagem dessa área que sofrem influência direcionada a processos de deposição e erosão numa velocidade percebida em acompanhamento feito por fotografias aéreas de 1954, 1961, 1967, 1978, 1988, 1990 e imagens de satélite Lansat e Ikonos 2000 e 2002, nos trabalhos de comparação realizados por Nascimento (2002).

É de fundamental importância o conhecimento prévio e detalhado da área em estudo para se entender a relação entre o meio natural e o espaço produzido nesta zona costeira. Esse reconhecimento compreende informações sobre as formas e a dinâmica natural e social do local, tais como compartimentação geomorfológica e suas características de unidades morfológicas que compõem o relevo. Destacando ainda, a importância dos fatos relacionados às características intrínsecas do solo, da geologia e da hidrogeologia e também o uso do solo pelas atividades produtivas (sal, petróleo e camarão).

A tecnologia na área do geoprocessamento disponibiliza ferramentas de grande utilidade para embasar os estudos das organizações espaciais, permitindo pesquisas mais acuradas a respeito da estrutura e dinâmica dos sistemas inclusos no campo de ação em estudo. Para a realização do presente trabalho, foram interpretadas imagens de satélite Landsat 5 sensor ETM e mosaicos de fotos aéreas, que foram inseridas em um SIG para que fosse possível a sua comparação no tempo e no espaço. A partir de observações de campo foram definidas as classes de maior relevância para o nosso estudo (salinas, carcinicultura, bases petrolíferas, áreas de inundação, solo exposto, águas continentais, caatinga, dunas fixas, dunas móveis e manguezal), que posteriormente foram transformadas em mapas de uso do solo.

No levantamento dos dados para estudo da área, foi verificado que pouca alteração ocorreu nos 30 anos em tela, o crescimento da atividade petrolífera do inicio da década de 1980 até hoje apresentou poucas mudanças na observação espacial. A atividade salineira que estava presente no ano de 1978 com um uso de 17,6\% passou a ocupar em 2008 uma porção de 22,6\%, tendo um aumento aproximado de $5 \%$ em trinta anos; a carcinicultura que teve sua presença na década de 1990 apresentou um elevado crescimento no uso do solo, pois na Imagem de 1998 apresentava $0,45 \%$ e apresenta atualmente $6,59 \%$. Na excursão de campo observamos que 
grandes áreas utilizadas no passado para a atividade salineira, hoje se encontram preparadas para a carcinicultura e que as áreas de exploração petrolífera ocupam salinas, praias e tabuleiros, em 1988 apresentou uma porcentagem de 0,07\% e atualmente ocupa 0,46\%, tendo crescido 50\% nos últimos 10 anos.

Embora a variação da ocupação da área tenha sido pouco expressiva, a carcinicultura mostrou um crescimento de $1200 \%$ em apenas 10 anos. No tocante a atividade petrolífera, mesmo com o crescimento da produção, não houve demonstração de um aumento impactante no uso do solo na área de estudo em 26 anos de exploração, devido a utilização de áreas já degradas ou áreas de menor impacto ambiental.

\section{METODOLOGIA}

Os dados coletados foram submetidos ao processamento, análise e integração. Fazendo a correlação dos mesmos, o que possibilitou uma melhor compreensão dos processos naturais e antrópicos na área estudada. Como ilustração apresenta-se um esboço do roteiro metodológico adotado (Figura 2).

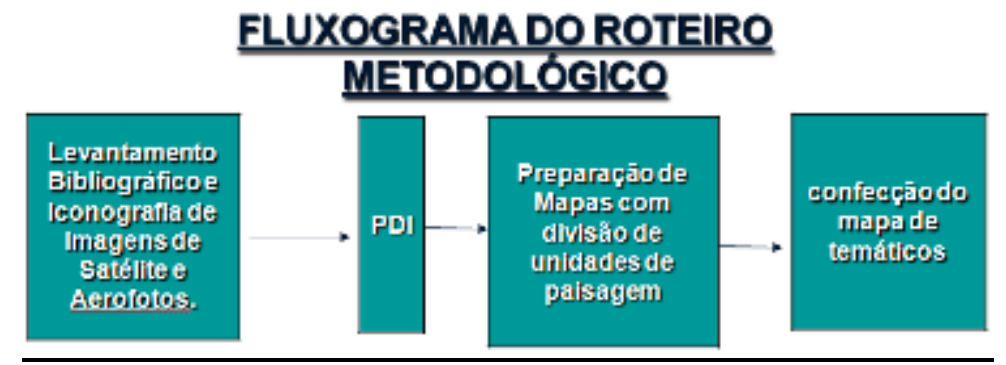

Figura 2: Esquematização simplificada do procedimento metodológico.

Para a determinação das classes de uso do solo através de imagens de satélite, foi utilizado um processamento digital de imagens, que é a composição colorida. Utilizando as imagens do sensor ETM do satélite Landsat-5, a composição colorida da área de estudo que mais destacou e diferenciou os objetos foi a RGB 543. A partir desta composição colorida, foi feita a separação das classes em cada uma das imagens landsat TM dos anos 1988, 1998 e 2008. O mangue foi a feição de visualização mais fácil devido a sua cor verde escuro característica nesta composição (Figuras 3 e 4). As dunas móveis apresentam uma coloração branca-amarelada, tornando sua distinção mais fácil. Desta maneira, cada uma das classes de uso e ocupação do solo possui uma cor e também uma geometria característica, inerente de cada uma delas, o que tornou viável a geração do mapa mesmo de anos anteriores onde determinadas feições podem não mais existir atualmente. 


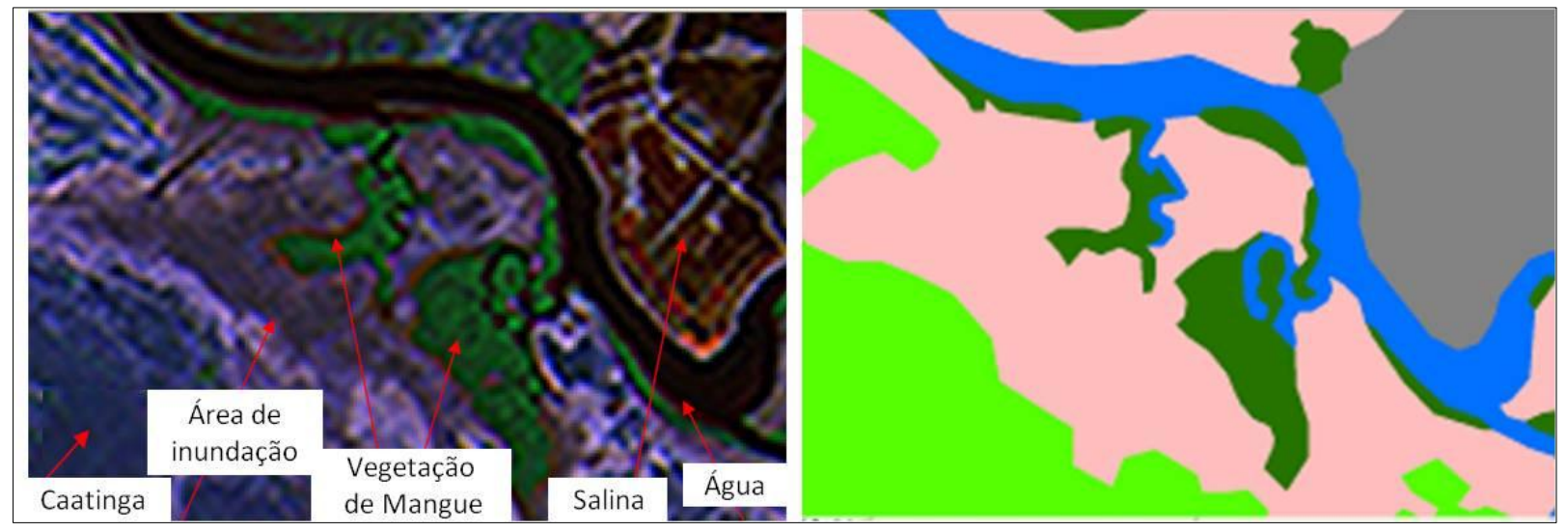

Figura 3: Identificação de feições em produto imagem e mapa resultante de feições
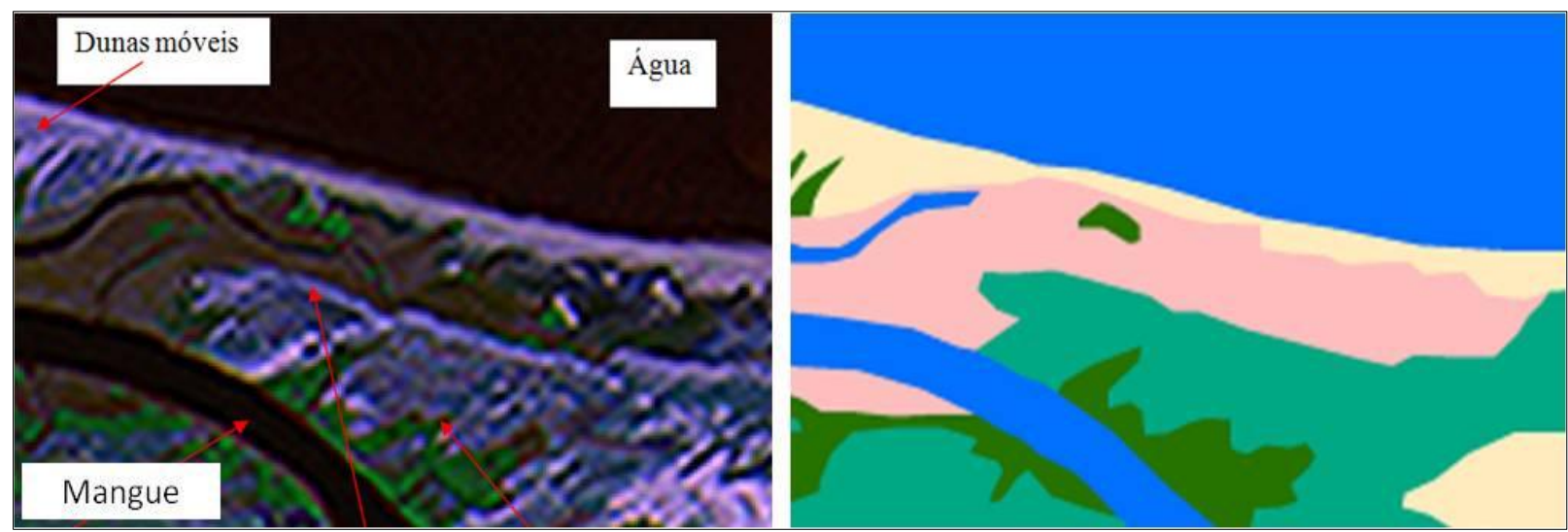

Figura 4: Outro ponto da mesma imagem e seu mapa resultante

Como é possível observar nas imagens Landsat, a resolução, ou o menor tamanho de objeto que pode ser reconhecido, é um grande entrave para a interpretação, principalmente em escalas de detalhe. Como o enfoque do trabalho é regional, estas imagens se adequam bem ao uso e possuem a vantagem de cobrir uma maior faixa temporal, o que não acontece com as imagens de alta resolução espacial.

Outra ferramenta utilizada foram as fotos aéreas do ano de 1978, tendo em vista a não existência de boas imagens de satélite nesse ano. Embora este produto seja em tom de cinza, ele ainda possibilitou uma boa demarcação de unidades para o ano de 1978.

As bases petrolíferas não são tão visíveis nas imagens do satélite Landsat devido a seu tamanho diminuto, para auxiliar a determinação das locações para o ano de 2008 foram utilizadas imagens de satélite Quickbird. A partir da identificação nas imagens de alta resolução espacial, as locações dos poços foram encontradas nas imagens Landsat. Para a determinação das áreas assumiu-se o valor médio das bases de 60×120m, multiplicado pelo número de pontos detectados. A parte do oceano foi retirada do cálculo para facilitar a visualização das porcentagens das outras classes, gerando assim a porcentagem de cada classe em relação ao total menos o oceano. 


\section{RESULTADOS E DISCUSSÕES}

Foram confeccionados mapas geológicos, geomorfológico, pedológico e de uso do solo, a partir da Imagem Landsat 5 TM 2008-07-19. Utilizando como base a imagem com a sobreposição das linhas do mapa de Souto (2004) e a partir deste ponto, iniciamos o ajuste das mesmas com a imagem que representa a situação atual. Foi feito o cruzamento das imagens pretéritas (1978, 1988 e 1998) com a imagem de 2008, induzindo a animação dinâmica da paisagem. O resultado foi à confecção de mapas de uso do solo para cada década estudada. No mapa de 2008 está a distribuição das classes de uso atual. Assim, com as informações de uso do solo sendo medida a área territorial de cada atividade como também de cada unidade geoambiental.

Baseado no mapa de uso do solo já confeccionados, calculamos a área das classes de unidades para em seguida realizar a interpretação da dinâmica das atividades produtiva e feições naturais da paisagem (Figuras 5, 6, 7 e 8).

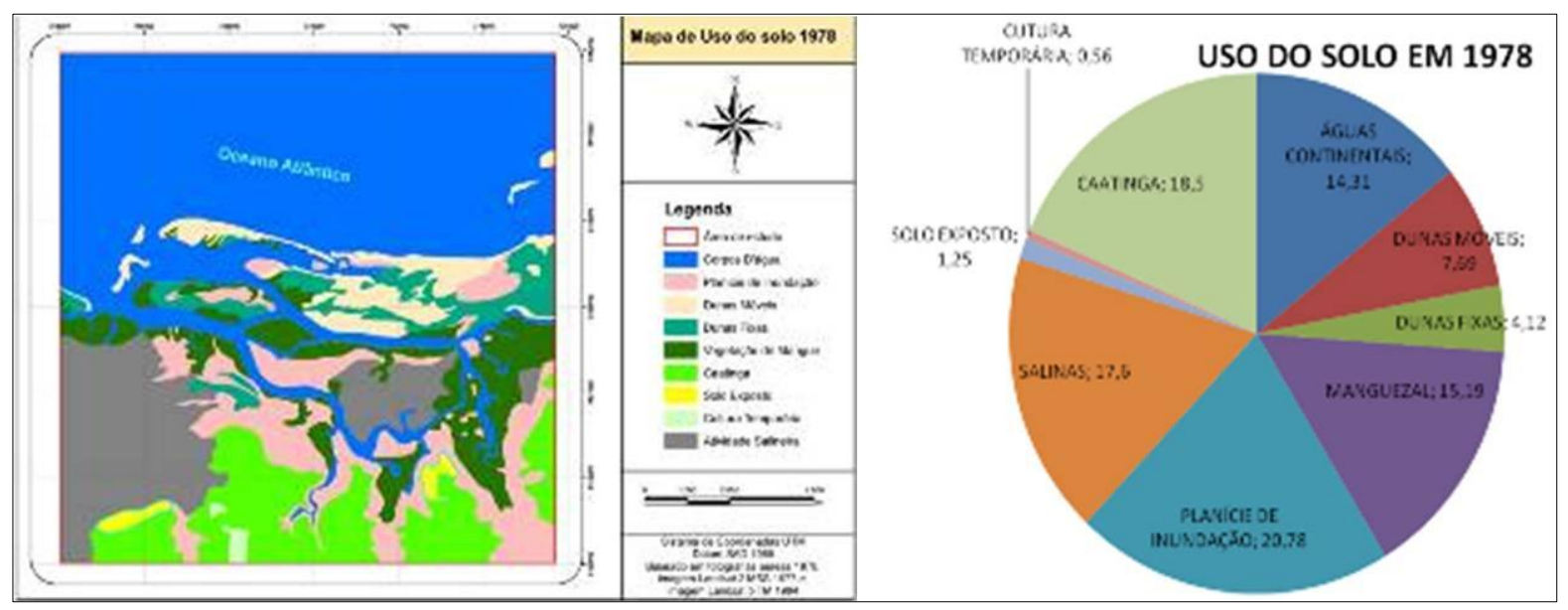

Figura 5: Mapa de uso do Solo e percentual na área de estudo em 1978

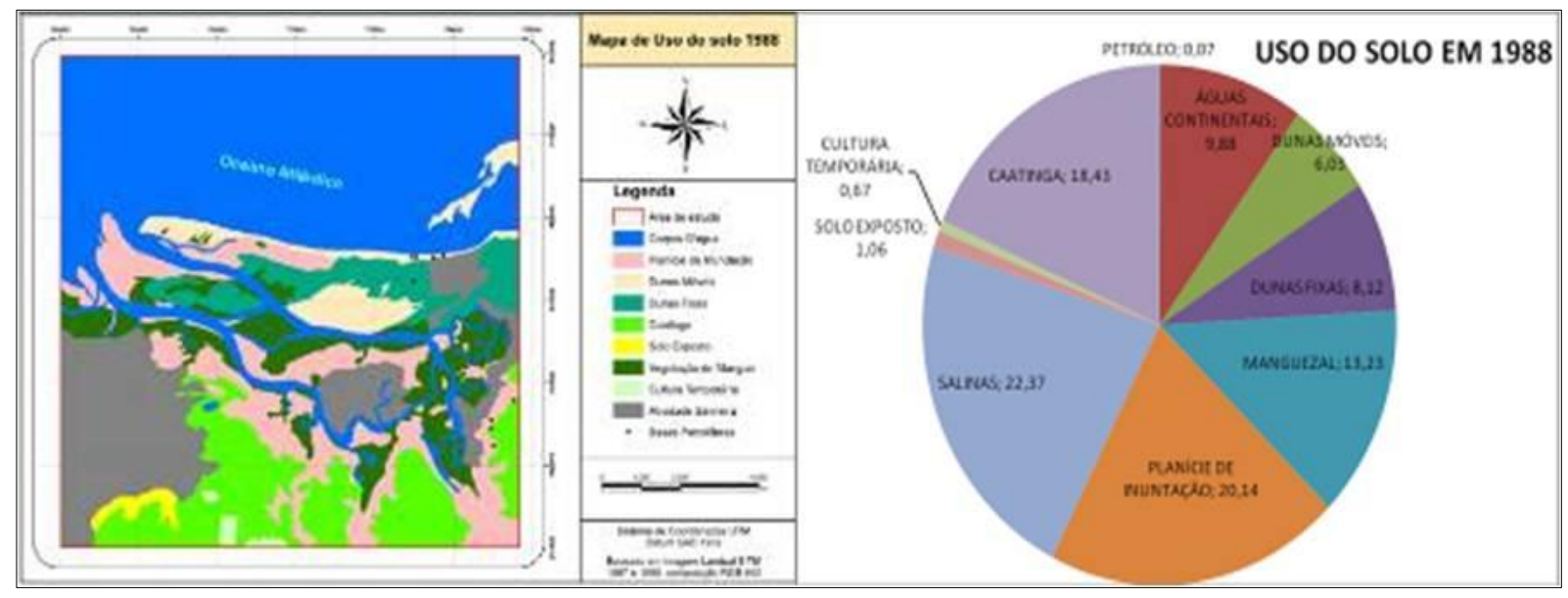

Figura 6 : Mapa de uso do solo e percentual na área de estudo em 1988. 


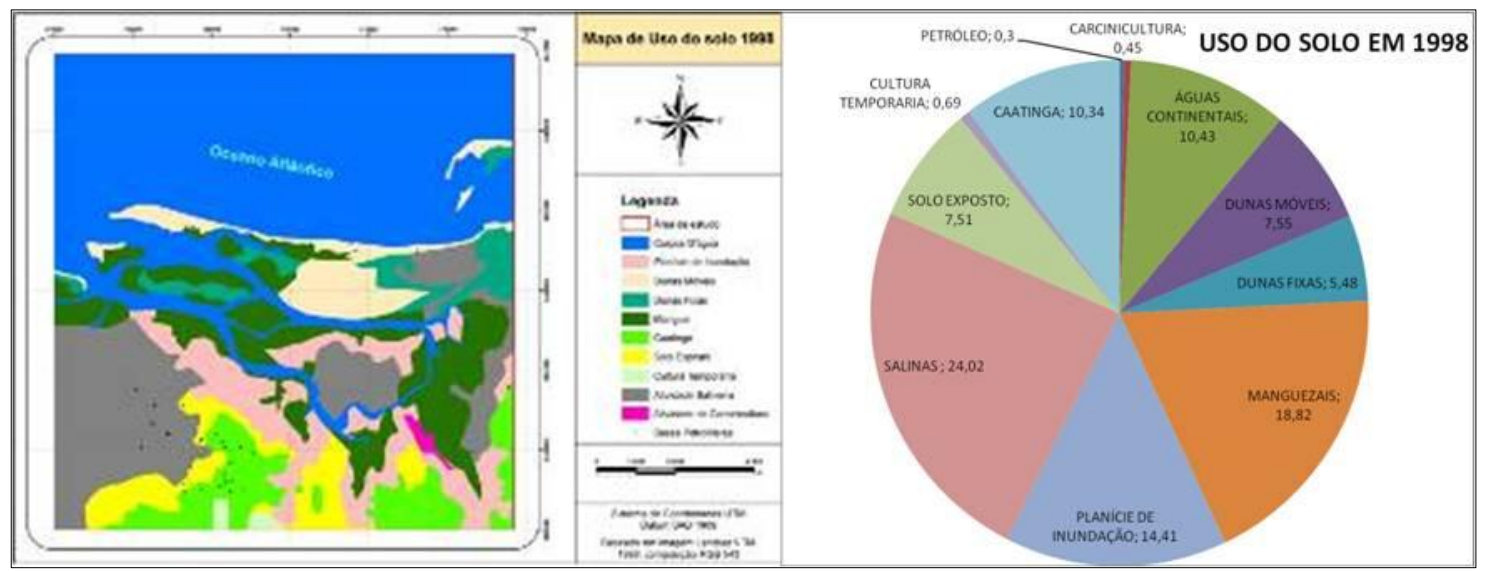

Figura 7: Mapa de uso do Solo e percentual da área estudada em 1998

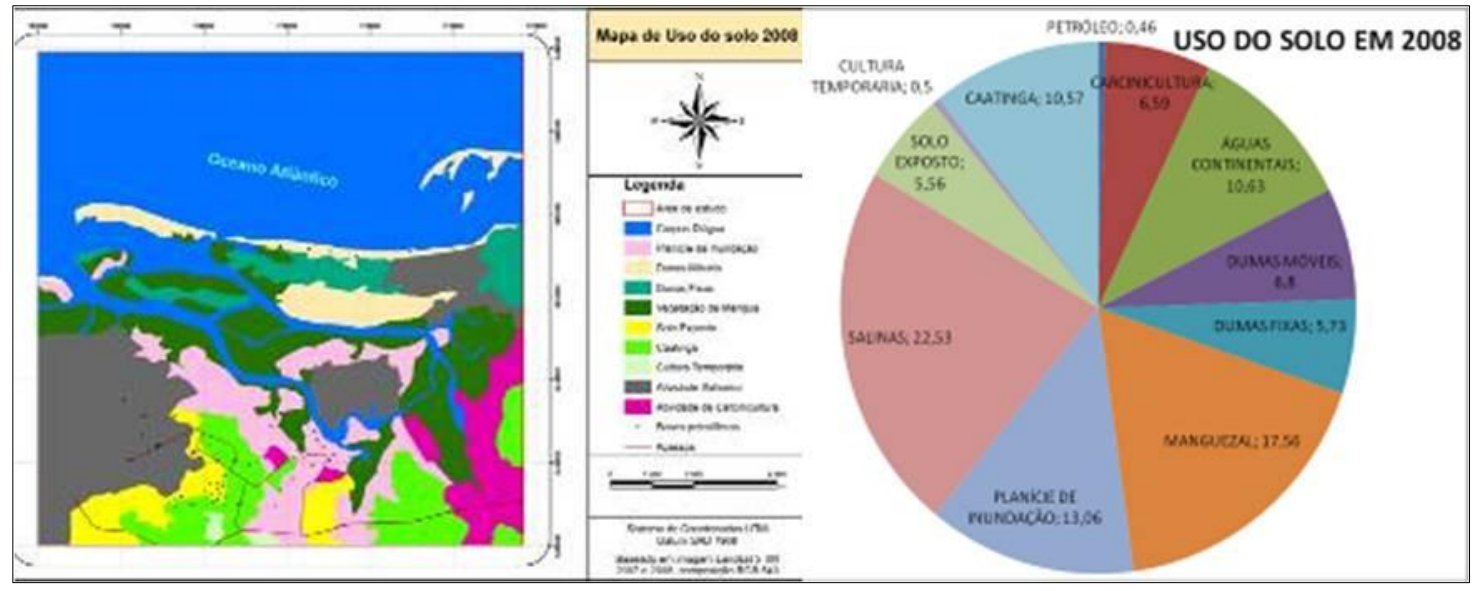

Figura 8: Mapa de uso do Solo e percentual na área estudada em 2008

Comparando as décadas em questão, percebemos que as mudanças ocorridas em alguns momentos registraram que a ocupação pela atividade da carcinicultura, apresentou alteração nas condições naturais, especialmente nas áreas de planícies de inundação. No tocante a atividade salineira, podemos dizer que ocorreu ocupação das áreas de planície de inundação, apresentando mudanças significativas em seu ambiente natural. A nível de informação obtida no gráfico, o crescimento da atividade petrolífera não apresentou grande expressão para nossa escala de trabalho, devido a ferramenta utilizada apresentar uma baixa resolução.

A pequena área perdida pela salina no ano de 1998 é recuperada pela carcinicultura, (Figura 9 e Tabela 1). Devido ao uso diferenciado e dinâmico do solo, foi observada pouca alteração na vegetação existente. As áreas de ocupação das atividades produtivas estão mais nas planícies de inundação, tabuleiros e faixas litorâneas. Nas duas últimas décadas estudadas, observou-se uma redução considerável da vegetação da caatinga e em contra partida um aumento da área em solo exposto apresentando um provável indício de desmatamento (ver Figura 9 e Tabela 1). 
Tabela 1- Porcentagens e áreas das feições no intervalo de estudo de 30 anos.

\begin{tabular}{c|c|c|c|c|c|c|c|c}
\hline \multirow{2}{*}{$\begin{array}{c}\text { ATIVIDADE } \\
\text { PRODUTIVA }\end{array}$} & \multicolumn{2}{|c|}{ ANO 1978 } & \multicolumn{2}{c|}{ ANO 1988 } & \multicolumn{2}{c|}{ ANO 1998 } & \multicolumn{2}{c}{ ANO 2008 } \\
\cline { 2 - 9 }$\left(\mathrm{km}^{2}\right)$ & $\%$ & $\begin{array}{c}\text { Área } \\
\left(\mathrm{km}^{2}\right)\end{array}$ & $\%$ & $\begin{array}{c}\text { Área } \\
\left(\mathrm{km}^{2}\right)\end{array}$ & $\%$ & $\begin{array}{c}\text { Área } \\
\left(\mathrm{km}^{2}\right)\end{array}$ & $\%$ \\
\hline PETRÓLEO & - & - & 0,13 & 0,07 & 0,27 & 0,30 & 0,41 & 0,46 \\
\hline CARCINICULTURA & - & - & - & - & 0,4 & 0,45 & 5,83 & 6,59 \\
\hline SALINAS & 14,10 & 17,60 & 19,93 & 22,37 & 21,13 & 24,02 & 19,95 & 22,53 \\
\hline $\begin{array}{c}\text { CULTURA } \\
\text { TEMPORÁRIA }\end{array}$ & 0,45 & 0,56 & 0,59 & 0,67 & 0,60 & 0,69 & 0,44 & 0,50 \\
\hline $\begin{array}{c}\text { ÁGUAS } \\
\text { CONTINENTAIS }\end{array}$ & 11,46 & 14,31 & 8,8 & 9,88 & 9,18 & 10,43 & 9,41 & 10,63 \\
\hline $\begin{array}{c}\text { PLANÍCIE DE } \\
\text { INUNDAÇÃO }\end{array}$ & 16,64 & 20,78 & 17,94 & 20,14 & 12,67 & 14,41 & 11,56 & 13,06 \\
\hline MANGUEZAL & 12,17 & 15,19 & 11,78 & 13,23 & 16,56 & 18,82 & 15,54 & 17,56 \\
\hline DUNAS MÓVEIS & 6,16 & 7,69 & 5,37 & 6,03 & 6,64 & 7,55 & 6,02 & 6,80 \\
\hline DUNAS FIXAS & 3,30 & 4,12 & 7,24 & 8,12 & 4,82 & 5,48 & 5,07 & 5,73 \\
\hline SOLO EXPOSTO & 1,00 & 1,25 & 0,94 & 1,06 & 6,61 & 7,51 & 4,92 & 5,56 \\
\hline CAATINGA & 14,81 & 18,50 & 16,42 & 18,43 & 9,10 & 10,34 & 9,36 & 10,57 \\
\hline & & & & & Fonte - Pesquisa de campo
\end{tabular}
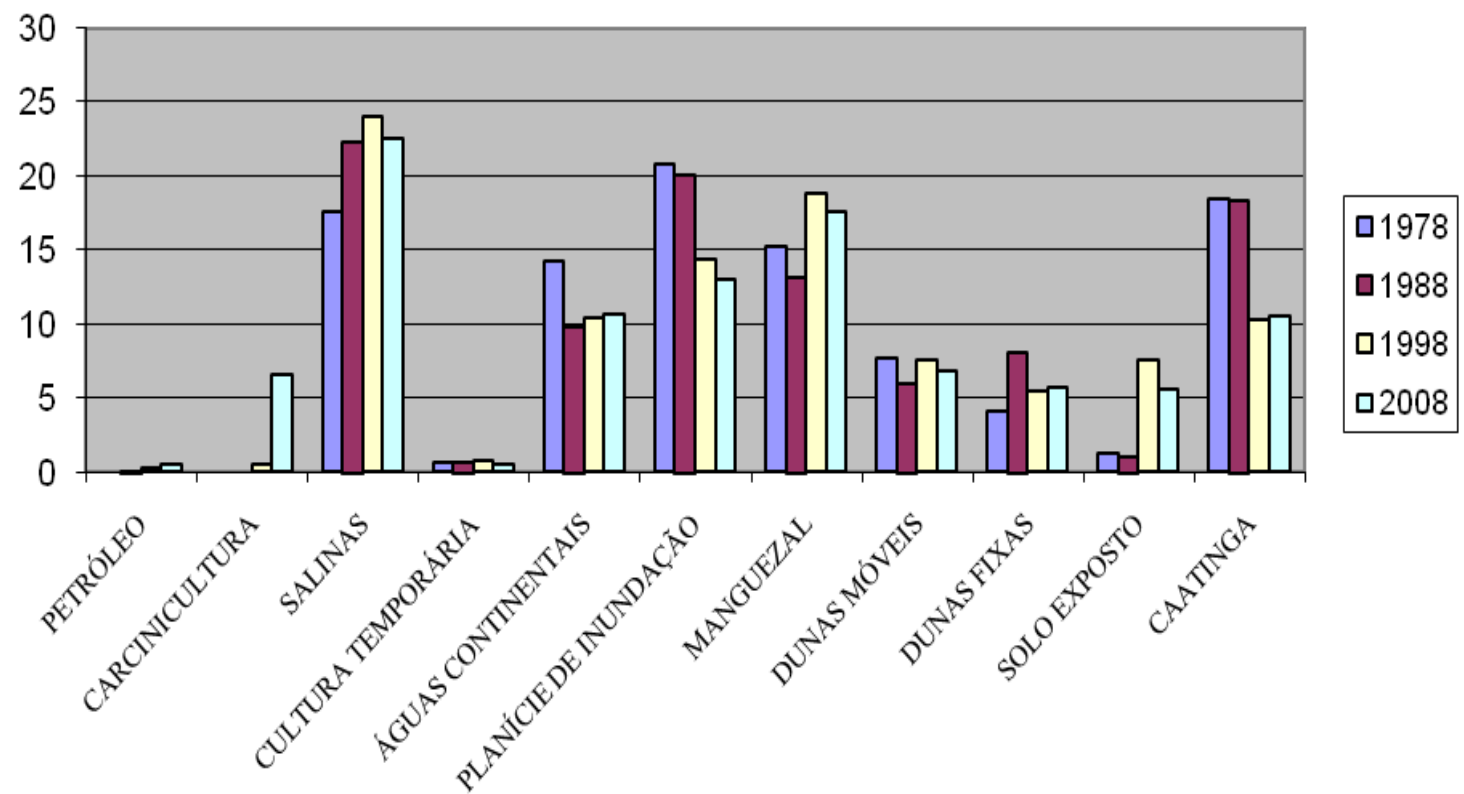

Figura 9: Gráfico Indicando a dinâmica das classes nos trinta anos (1978/2008)

\subsection{Dinâmica das salinas}

As salinas tiveram aumento entre 1978 e 1988 de 5\% da área ocupada. No período de 1988 á 1998, esta área manteve-se praticamente inalterada com uma pequena tendência de crescimento com 2\%. Entre 1998 á 2008 as salinas diminuíram suas áreas em 2\%, período de grande crescimento da área ocupada pela atividade da carcinicultura. As bases petrolíferas ocuparam as interfaces dos tanques cristalizadores (base e vias de acesso). Esta atividade 
ocupando uma grande porção a sudeste da área de estudo, porção central e uma área interdunas fixas a nordeste, porção só ocupada a partir da imagem de 1988, onde apresentou crescimento, atingindo uma área de 19,95 km² em 2008.

\subsection{Dinâmica da atividade petrolífera}

A atividade petrolífera teve inicio na área em tela, em 1982, porém devido a baixa resolução das imagens landsat 5 TM, não identificamos áreas de uso até 1988 . Vindo a ser mais visível o seu crescimento a partir das imagens de alta resolução que possibilitaram reconhecer e até medir áreas ocupadas por esta atividade. A pouca expressão no uso e ocupação do solo não é um indicativo para o crescimento desta atividade, pois vários poços são direcionais, onde as bases são perfuradas em locações de outros poços já existentes. O cruzamento dos mapas de 1978 a 2008 mostraram que esta atividade não provocou a supressão da vegetação de manguezal. A maioria das bases de poços, estação coletora e faixa de dutos encontrando-se em áreas da classe de vegetação de caatinga, solo exposto e salinas.

\subsection{Dinâmica da carcinicultura}

A carcinicultura apresenta seu registro nas imagens de 1998 e 2008. Esta atividade se desenvolveu em áreas de planície de inundação e ocupando antigas salinas. O território da carcinicultura subiu de $0,40 \mathrm{~km}^{2}$ para $6,83 \mathrm{~km}^{2}$, percentuando em $6,59 \%$ da área de estudo que tem um total $88,52 \mathrm{~km}^{2}$ da porção continental. O primeiro registro que obtivemos neste trabalho foi uma ocupação de uma área de planície de inundação numa porção SE da área de estudo. Hoje observamos o crescimento dos viveiros mais para leste, ocupando antiga salina e planície de inundação, além de duas áreas observadas na porção central. A luz de uma melhor compreensão do gráfico apresentado, podemos acrescentar que foi possível entender toda a dinâmica dos acontecimentos, referentes a evolução das atividades produtivas, apontando a carcinicultura como atividade que merece uma analise mais cuidadosa no decorrer das próximas décadas, pois apresentou uma disparidade no crescimento. Entendemos a necessidade de produzir, porém uma análise ambiental previa é de fundamental importância para o equilíbrio do ecossistema.

\subsection{Dinâmica da vegetação natural e uso antrópico}

Nesta categoria incluímos a vegetação de manguezal, vegetação de caatinga e solo exposto (área de pastagem e cultura temporária), como contexto natural e antropisada, fora do contexto do uso do solo pelas atividades de salinas, petróleo e carcinicultura, para que possam ser analisadas e comparadas em sua evolução natural sem a interferência das atividades produtivas. A partir da década de noventa houve um grande aumento de solo exposto provavelmente em função do desmatamento para pastagem e culturas temporárias, ou um provável desmatamento para a retirada de lenha. Através da analise seqüencial das imagens orbitais, a cada década num período de 30 anos foi possível perceber a redução da área de vegetação de caatinga em aproximadamente $40 \%$, coincidindo com a área de solo exposto com um grande salto na década de 1990 e apresentando 5\% de solo exposto na ultima imagem. Enquanto que em 1978, a área de solo exposto era apresentada por pequenas porções 
localizadas a SE e SW da área mapeada, apresentou pequena expansão à NW da área de estudos no ano de 1988, mas apresentando nos anos de 1998 e 2008 grande avanço em direção NE, encontrando-se com a planície de inundação e formando vasto trecho desnudo.

\section{CONCLUSÕES}

Os estudos realizados neste artigo conduziram-nos as seguintes considerações. A evolução observada de uso e ocupação da área em estudo, predominante em produção de Petróleo, Carcinicultura e salinas, fontes que favoreceram o município de Macau na área econômica, vem sendo o piloto no desenvolvimento local no decorrer das décadas vivenciadas. Neste trabalho foi possível perceber que, mesmo que o homem modifique a paisagem pelas suas necessidades, a natureza também faz os seus ajustes determinado pelas suas condições. De acordo com o que se considera sobre paisagem podemos acrescentar ainda que, se esta poderá ser modificada com o tempo e a ação, é pouco provável existir um conceito realmente absoluto.

Com a construção de cartas temporais baseadas na interpretação das imagens do satélite Landsat 5, identificamos a dinâmica do uso do solo onde a atividade salineira ocupa uma maior área (anexo 5, 6, 7 e 8). A atividade de carcinicultura hoje ocupa 6,59 \% de uma área antes utilizadas pelas atividades salineiras, como também áreas de planícies de inundação. Percebeu-se que, a atividade de carcinicultura teve uma dinâmica de crescimento muito expressiva, no tocante ao reaproveitamento do solo antes utilizado pelas atividades de produção do sal. No entanto, quanto a atividade petrolífera, esta utiliza uma pequena área de ocupação e uso do solo e encontra-se nas áreas de tabuleiro e em torno das área de salinas e praias. Os resultados ainda nos evidenciaram a importância da utilização de imagens de satélites e aplicação do sistema de informações geográficas (SIG) no fornecimento dos dados para a identificação de uso do solo e monitoramento ambiental. Contribuindo assim com a gestão quanto ao conhecimento do uso do território no litoral setentrional de Macau.

O presente estudo realizado considera a análise temporal uma ferramenta de grande importância e necessária para contribuir com a gestão ambiental da área, valorizando não só o município, como também, o Estado do Rio Grande do Norte.

A partir dos procedimentos metodológicos adotados obtivemos os resultados efetivos descritos nos objetivos deste trabalho. Elaboramos uma planilha que indica que a maior porção da área em estudo é ocupada pela atividade salineira e a menor ficando com as culturas temporárias. A carcinicultura teve um grande avanço no uso do solo e a atividade petrolífera só teve sua quantificação possível com a ajuda de imagens de alta resolução.

\section{AGRADECIMENTO}

Petrobrás, Empresa na qual o primeiro autor trabalha. Programa de Pós-Graduação e Pesquisa em Geografia, programa na qual foi realizada a pesquisa. 


\section{REFERÊNCIAS BIBLIOGRÁFICAS}

1. SOUTO, M. L. V. S. Análise Multitemporal dos elementos geoambientais da região da ponta do Tubarão, área de influencia dos campos Petrolíferos de Macau e Serra, município de Macau/RN. 2004. 112 p. (551.468 S726a DISSERT). Dissertação (Mestrado em geodinâmica) Universidade Federal do Rio Grande do Norte - PPGG, Natal. 2004.

2. NASCIMENTO, M. C. Uma Contribuição para a Caracterização das Unidades Ambientais de Ecossistema Costeiro compreendido entre a Barra do Corta cachorro (Macau) e o Rio Porto do Capim (Guamaré), Estado do Rio Grande do Norte. Natal. 2002, 13 p. (não publicado).

3. GOVERNO DO RN - Perfil do seu município. Disponível em: <http://www.rn.gov.br /secretarias/idema/perfil_m.asp>. acesso em: 25.abr.2007.

4. LANDSAT INFORMAÇÕES. Disponível em: <http://www.dgi.inpe.br /Suporte/files/CamerasLANDSAT57_PT.php>. acesso em: 04.set.2008.

5. MAPA DE SOLOS MACAU. Disponível em: <http://www.uep.cnps.embrapa.br/solos/rn/ macau.pdf >. acesso em: 14.out.2007.

6. SECRETARIA DO MEIO AMBIENTE E DOS RECURSOS HÍDRICOS-BACIAS HIDROGRÁFICAS. Disponível em: <http://www.semarh.rn.gov.br/consulta/cBacia.asp>.acesso em: 25.ago.2007. 